\title{
A Study of Taiwanese College Students' Responses to a Blog-based English Writing Project and its Effectiveness
}

\author{
Adam Ting \\ Tatung University
}

\begin{abstract}
This study intended to explore Taiwanese college students' responses and their English writing performance after a blog-based English writing project. 65 non-English major college students participated in this study. The EG received blog-based writing exercises, while the CG took traditional writing training. All subjects were required to take a pretest and a post-test writing and answer a questionnaire of blog-based English writing project. The major findings included, first, the EG displayed significant difference from the $C G$ in the post-test writing, particularly in content, organization, and average length of sentences; second, there is no significant difference between the subjects' attitude toward the multi-level writing assessment on their post-test writing; third, the EG subjects held positive attitude toward the Blog-based English writing project for its convenient working platform for students to upload or modify their own assignments, to obtain the teacher's corrective feedbacks, to observe peers' model sample works or peers' comments, and most importantly, to analyze the subject learning process and improvement. In light of the findings from the study, some pedagogical implications are suggested.
\end{abstract}

\section{Introduction}

With the considerable advance of computer technology, network-assisted language learning has become increasingly important for language students, particularly the extraordinary functions available to save and retrieve data beyond ordinary time and space restrictions [19]. Many online systems have helped users in their work, studies, tours, life routines or even to develop speech communities. There is no exception for the blog system. According to Ward, a blog can allow people to make individual comments on a given topic in forum discussions in any place at any time [18]. As the initial topics in forum discussions become more and more resourceful, the proposer will obtain more valuable information for further discussions. Therefore, the blog or the web log provides its own feedback and has been becoming more and more popular for online communication since the late 1990s. Ward claimed that blogs could provide student writers with an instructional platform for writing compositions, reading and making comments online [18]. Stiler also claimed that frequent exposure to the constructive comments of peers not only helps reinforce the student writers' motivation, but also helps reduce their habitual mistakes when doing assigned writing tasks [15].

Writing is a process including the procedures of gathering, formulating and refining ideas, and it is suggested that writing teachers should be involved throughout the process. In the process of gathering ideas, teachers can encourage students to collect data relevant to the assigned topic. It is also the teacher's responsibility to assess the students writing once the final draft is done.

In traditional writing instruction, the teacher's assessment is idiosyncratic and authoritative. Many teachers give the student's work a holistic score based on an overall impression of the script [20]. Marking a student's writing on the basis of a general impression does allow for prompt grading; however, in most cases, the teacher fails to consider the detailed elements of the writing. To deal with this problem, recently some alternative ways for assessing work have been proposed, such as peer assessment and self-assessments.

Self-assessment refers to a process whereby students make judgments about their own learning, particularly about their achievements and the outcomes of their learning [3]. It enables the students to be aware of what they have learned and thus they are able to adjust the direction of their subsequent learning.

Peer assessment is a process whereby groups of individuals grade their peers [8]. It serves as an alternative assessment for students who benefit from the input of peers with a similar educational background. It offers reliability and validity of assessments, though some students may be doubtful of its effectiveness [17]. For peer assessment to be effective, it is necessary for students and the instructor to jointly determine a set of well-organized criteria in advance, so that students can follow specific principles in their peer assessment [6].

Ideally, a blog-based writing environment can provide a working platform for individual student to post 
his or her writing, and then receive feedback or comments from the teacher or peers without time and space constraint; in this way, the student is likely to develop more positive writing attitude and become a motivated writer.

Although English writing has been strongly advanced in senior high schools throughout Taiwan as part of the standardized university examination process, many students in Taiwan still have not developed any great interest in English or the ability to produce English writing of high quality.

Since the English writing performance of many senior high school students in Taiwan has been less than satisfactory, it has become necessary to search for alternative CMC tools, such as blog-based writing, to help promote students' English writing. A number of studies have been conducted with the focus on facilitating the students' learning motivation. This study aimed to explore to what extent the multi-level writing assessment and a blog-based English writing project can help students to improve their writing performance and their attitude toward writing. The research questions are as follows.

1. Is there any significant difference in the English writing performance for the EG and the $\mathrm{CG}$ in the multi-level writing assessment project?

2. Are there any significant differences in the EG and the CG students responses to the teachers' assessment, the peer assessment, and self-assessment?

3. How is the EG students responses to the blog-based English writing project (BBEWP)?

\section{Literature review}

With its unique communicative functions for website hosts and audience, a blogging has been adopted as a pedagogical instrument for teachers and students [1]. Through blogging, the teacher and the students can exchange different ideas and feedback with each other beyond the constraint of ordinary classroom teaching. Compared with traditional pen-and-paper writing instruction, Blog-based writing instruction enriches more language learning. First, blogs can provide a valuable dimension of authenticity to students' reading and writing experiences in the target language [14]. Second, blogs can energize and engage students who are quiet in class due to shyness or anxiety [12]. Third, blogging provides a forum for genuine communication among all the students in an L2 class, which signifies the potential for all students to feel that they belong to a class community [13]. Arslan and Sahin-Kazil's explored how the use of blog software facilitated the writing process of English students [2]. They found that blog-integrated writing instruction resulted in greater improvement in the students' writing performance.

Traditional language instruction is necessarily involved in teacher's assessment. Teacher's assessment refers to the teacher's grading of students' learning outcome after a specific lesson is completed. Traditionally, teachers assess the students' work or performance by giving a holistic score based on an overall impression [20]. On the other hand, the reliability of teacher's assessment has been discussed in the literature and there is evidence that teacher's assessments vary greatly [11] [17]. In addition, general assessment studies on teacher behavior in language classes have shown that teachers spend a relatively little time assessing individual student's performance [7]. It is apparent that if the assessment of the student's learning depends on the teacher's individual assessment, there may be problems with how objective the evaluation would be.

In addition to feedback from teacher's assessment, many researchers have proposed that peer assessment and student self-assessment for further assessing students' learning [8] [17]. Specifically, in peer assessment, students assess the achievement, learning outcomes or performance of their fellow students. This provides important additional sources to interpret students' learning.

Research on peer assessments showed that most of the studies supported the effectiveness of peer assessment in encouraging learning. For example, Topping reviewed 31 studies on the validity of peer rating [16]. He concluded that the majority of the studies showed acceptably high validity and reliability in a variety of fields. As for the fairness of peer assessments, Conway, Kember, Sivan and Wu's study indicated that students felt that peer assessment was a good method and they suggested students taking part in the assessment to make the assessments were more objective [5].

The self-assessment allows students to consider and specify the level, value or quality of their own work or performance [17]. When students are involved in the assessment process, they can be fully aware of their learning and thus manage to improve and intensify their learning. Brown and Abeywickrama indicated that self-assessment has an impact on the field of education since the ultimate purpose of education always is to help students to develop independency and autonomy to equip them for lifelong learning [4].

To sum up, to facilitate the usefulness of Blog-based writing, it may be feasible for an English writing instruction to adopt process writing practice, including the student writer self-assessment, teacher assessment, and peer assessment, in this way, students are able to do multiple writing on the blog and gradually develop their writing skills.

\section{Methodology}

The subjects in this study included 65 non-English major college students at the third year in a private university in Taipei. The subjects came from two different writing classes. One class was assigned to take computer-mediated writing instruction, while the other 
class took traditional wiring lessons, that is, they would take paper-based writing instruction and exercise. In view of different treatments, the former served as the experiment group (EG) and the latter served as control group (CG). The subjects in both groups were intermediate EFL learners, who did not receive formal English writing instruction with multi-level writing assessments. During the one-year English writing course, all the subjects received the same instructions and did the same amount of writing exercises; each writing exercise went through a whole assessing process, including the teacher assessment, peers' assessment, and the subject's self-assessment.

Two instruments were used in the study, including students short essay writing, and a Questionnaire on the students response to multi-level English writing assessment projects. Two compositions that each subject produced in the pretest and post-test writing were collected. Two raters, the researcher and an English teacher, were responsible for assessing the student writing, using an analytical scoring scale adapted from Brown and Abeywickrama [4]. The inter-rater reliability was reliable (Spearman's correlation Coefficient of pretest $r=.693$, post-test $r=.554, p$ value of the both tests $=.00<.01)$. In addition, the questionnaire was designed by the researcher to understand the EG and the CG's responses to the English writing and to the three types of writing assessments. There were 40 items divided into five categories, including the subjects' writing attitude, the teachers macro and micro assessment, peers and self assessment. The subjects' responses were recorded using a five-point Likert scale-strongly agree, agree, neutral, disagree and strongly disagree. The reliability of the questionnaire is .955 and the validity is .811 respectively, which indicated that the reliability coefficient of the questionnaire is considered to be very reliable.

\section{Results and discussion}

The result of the subjects overall writing performance in the pre/post-test were displayed in Table 1. Compared with their writing performance in the pretest, the subjects in the EG showed significant difference in the post-test $(t=-3.40, p=.00<.01)$. The same is true for the CG, $(t=-3.63, p=.00<.01)$. The results imply that the writing performance for the subjects in the EG and the CG improved because of the multi-level assessment writing project.

In order to further investigate to what extent the subjects have improved their English writing performance in the post-test writing, it would be necessary to compare the subjects' writing performance in terms of analytical scores, including content, organization, grammar, vocabulary, mechanics, and average words per sentence
Table 1. Comparison of the EG's and the CG's English Writing Performance in Terms of Seven Categories

\begin{tabular}{llllll}
\hline Cate & Group & Pre M(SD) & Post $\mathrm{M}(\mathrm{SD})$ & \multicolumn{1}{c}{$t$} \\
\hline writing & EG & $11.04(1.31)$ & $12.05(2.10)$ & -3.40 & $00^{* *}$ \\
perf. & CG & $10.34(1.35)$ & $11.71(2.13)$ & -3.63 & $.00^{* *}$ \\
\hline \multirow{2}{*}{ Cont } & EG & $2.34(0.57)$ & $2.81(.079)$ & -0.33 & $.00^{* *}$ \\
& CG & $1.98(0.56)$ & $2.78(0.74)$ & -5.03 & $.00^{* *}$ \\
\hline \multirow{2}{*}{ Orga } & EG & $2.57(0.57)$ & $2.70(0.90)$ & -3.03 & $.00^{* *}$ \\
& CG & $1.91(0.58)$ & $2.59(0.67)$ & -4.55 & $.00^{* *}$ \\
\hline \multirow{2}{*}{ Gram } & EG & $1.90(0.43)$ & $2.26(0.660$ & -3.35 & $.00^{* *}$ \\
& CG & $1.85(0.48)$ & $2.00(0.78)$ & -1.09 & .28 \\
\hline \multirow{2}{*}{ Voca } & EG & $1.89(0.40)$ & $2.00(0.560$ & -1.05 & .30 \\
& CG & $1.85(0.39)$ & $1.93(0.60)$ & -0.68 & .50 \\
\hline \multirow{2}{*}{ Mech } & EG & $0.91(0.37)$ & $1.29(0.47)$ & -3.69 & $.00^{* *}$ \\
& CG & $1.00(0.32)$ & $1.14(046)$ & -1.54 & .14 \\
\hline Aver. & EG & $10.20(1.36)$ & $11.38(1.91)$ & -3.35 & $.00^{* *}$ \\
Words & CG & $10.51(0.39)$ & $11.55(0.36)$ & -1.75 & .92
\end{tabular}

Note. ${ }^{* *} p<.01, \mathrm{EG}=\mathrm{EG}(34), \mathrm{CG}=\mathrm{CG}(27), \mathrm{M}=$ Mean, $\mathrm{SD}=$ Standard Deviation

The assessment of content in this study mainly evaluates the subjects writing skills regarding the closeness to the topic, and the complete supporting ideas. The result of the subjects' writing performance in this category indicated that the EG made significant improvement in the post-test, $(t=-.33, p=.00<.01)$, compared with their pretest. Similarly, the CG also performed significantly better in their post-test than the pretest $(t=-5.03, p=.00<.01)$ after the writing project.

Organization of English writing refers to the structure of the composition. To be specific, it is to examine whether there is a topic sentence, well-developed supportive sentences of the main idea, and a concluding sentence. The subjects performance in this category is that, both the EG $(t=-3.03, p=.00<.01)$ and the CG $(t$ $=-4.55, p=.00<.01)$ displayed significant development in the post-test writing.

The assessment of the subject English written works in respect of grammar concerns the extent to which the grammatical errors may influence readability on the part of the readers. In this category, the EG and the CG displayed different results after the study. The EG made significant improvement in the post-test, $(t=-3.35, p$ $=.00<.01)$, while the $\mathrm{CG}$ did not show improvement in this category, $(t=-1.09, p=.28>.01)$.

The assessment of vocabulary in the subjects' composition aimed at evaluating the subjects' knowledge of vocabulary use, such as spelling, appropriateness of word use. As indicated in Table 1, there is no significant 
difference between the pretest and the post-test for the EG $(t=-1.05, p=.30)$ and the CG $(t=-.68, p=.50)$. The result is likely to indicate that even thought the subjects were able to produce better content and organization after receiving the English writing project in this study, they failed to display their vocabulary competence within a limited time. After all, vocabulary learning takes more time and efforts than other language skill learning.

The assessment of mechanics in the subjects' composition focused on inspecting the use of punctuation, capitalization, and format. As indicated in Table 1, there is a significant difference between the pretests and the post-tests for the EG $(t=-3.69, p=.00$ $<.01)$, but not for the CG $(t=-1.54, p=.14)$. In addition, the mean scores of the EG's post-test is higher than that of the CG $(1.29>1.14)$. Thanks to the development of computer software, like Microsoft Editing Software WORD, or built-in spelling check devices on the webpage, the EG subjects could check if the capitalization, punctuations are being wrongly used through the use of automatic examining function.

Since the EG showed significant improvement compared to the CG in terms of content, organization, grammar, and mechanics, it is needed to further compare the writing performance with respect to average length per sentence for the EG and CG. The results presented in Table 1 demonstrated that the subjects in the EG did have reveal significant improvement in their post-test writing, $(t=-3.35, p=.00<.01)$.

In addition to the subjects' writing performances in the post-test being compared, their responses to the multi-level writing assessment were investigated. The subjects' responses to the five main categories in the questionnaire included the writing attitudes, teacher's macro assessment, teacher's micro assessment, peer assessment, and self assessment. The results were discussed as follows. To begin with, the subjects overall responses to the questionnaires did not reveal significant difference between the EG and the CG; however, the average mean scores of the subjects responses to the five categories were higher than $3.65(\mathrm{SD}=.67)$, as shown in Table 2, which means both the EG and the CG regarded the multi-level writing assessment as helpful for their writing performance. On the other hand, among the three type assessments (teacher, peer, and self assessment), the average mean score in the category of teacher's micro assessment is $4.04(\mathrm{SD}=.52)$, which were significantly higher than their responses to other categories. In other words, both the EG and the CG considered the teacher's micro assessment beneficial to their written works. Teacher's micro assessment concerns the subjects' analytic scores in respect of organization, grammar, vocabulary and mechanics. The scores in these categories usually show the subjects' current competence of grammatical application and word uses in the writing. Besides, the mean score of 3.98 ( $\mathrm{SD}=.48)$ in the category of teacher's macro assessment, which is related to what extent the subject can present their ideas effectively in the writing, also indicated that the subjects in both groups viewed teacher's assessment as more favored than peer and self assessment. The results support Hyland's notation that teacher written feedback is highly evaluated by second language writers [9].

Table 2. Correlation among English Composition

Scores, Average Scores of Attitude and Four Major Categories in the Questionnaire for the Subjects

\begin{tabular}{|c|c|c|c|c|c|c|c|}
\hline & $\begin{array}{l}\text { Po } \\
\text { st }\end{array}$ & Att & $\begin{array}{l}\mathrm{T}-\mathrm{m} \\
\mathrm{ac}\end{array}$ & $\begin{array}{l}\text { T-m } \\
\text { ic }\end{array}$ & Peer & Self & M (S.D) \\
\hline Post & 1 & $\begin{array}{l}.278 \\
*\end{array}$ & .130 & .103 & $\begin{array}{l}-.15 \\
0\end{array}$ & $\begin{array}{l}-.01 \\
8\end{array}$ & $11.89(2.08)$ \\
\hline Att & & 1 & $\begin{array}{l}.748 \\
* * \\
* *\end{array}$ & $\begin{array}{l}.603 \\
* *\end{array}$ & $\begin{array}{l}.487 \\
* *\end{array}$ & $\begin{array}{l}.596 \\
* *\end{array}$ & $3.86(.39)$ \\
\hline $\begin{array}{l}\text { T-m } \\
\text { ac }\end{array}$ & & & 1 & $\begin{array}{l}.671 \\
* *\end{array}$ & $\begin{array}{l}.506 \\
* * \\
* *\end{array}$ & $\begin{array}{l}.530 \\
* *\end{array}$ & $3.98(.48)$ \\
\hline $\begin{array}{l}\text { T-m } \\
\text { ic }\end{array}$ & & & & 1 & $\begin{array}{l}.510 \\
* *\end{array}$ & $\begin{array}{l}.530 \\
* *\end{array}$ & $4.04(.52)$ \\
\hline Peer & & & & & 1 & $\begin{array}{l}.504 \\
* *\end{array}$ & $3.65(.67)$ \\
\hline Self & & & & & & 1 & $3.68(.66)$ \\
\hline
\end{tabular}

Notes: Post $=$ Post-test composition, Att $=$ Writing attitude, $\mathrm{T}-\mathrm{mac}=$ Teacher macro assessment, $\mathrm{T}-\mathrm{mic}=$ Teacher micro assessment, Peer $=$ Peer assessment, Self $=$ Self assessment, $* *$ $p<.01, * p<.05$

Pearson's correlation was used to test the hypothesis of a linear relationship between the subjects' writing score with their writing attitude and with the multi-level assessments. As indicated in Table 2, the subject writing attitude was significantly related to their responses to teacher, peer, and self assessment. On the contrary, the subject writing performance in the post-test did not reveal significant relation to their response to the three types of writing assessment. However, the subject writing attitude were significantly related to their writing performance $r(59)=.278, p<.05$

Given the results that the subjects' writing performance was related to the treatments, as shown in Table 1, and also with the writing attitude, as indicated in Table 2, a two-way ANOVA was executed to measure the effect of the treatments and the subject writing attitude on the writing scores in the post-test.

The ANOVA sources of variation result showed that there is no significant interaction between the treatment and the subjects writing attitude on their writing performance in the post-test writing, $\mathrm{F}(1,59)=4.442, p$ $>.05$. Table 3 summarized the mean scores, standard deviations of composition scores of the 4 groups for the 
interactive effect of treatment and writing attitude.

Table 3. Composition Between the EG and CG in terms of their Writing Attitude on the Post-test Writing

\begin{tabular}{lllll}
\hline Treatment & \multicolumn{1}{c}{ EG } & \multicolumn{2}{c}{ CG } \\
\cline { 2 - 5 } W-att & Mean (SD) & $\mathrm{N}$ & Mean $(\mathrm{SD})$ & $\mathrm{N}$ \\
\hline Low & $11.88(2.36)$ & 19 & $10.08(1.95)$ & 11 \\
High & $12.18(1.79)$ & 15 & $12.77(1.63)$ & 14 \\
\hline
\end{tabular}

As indicated in Table 3, for the EG, the subjects with high writing attitude performed better than those with low writing attitude, $(12.18>11.88)$. Likewise, for the CG, the subjects with high writing attitude produced even higher writing scores than those with low writing attitude, $(12.77>10.08)$. The result implies that an open-ended learning attitude, that is, willing to accept feedback from different sources, enables the subjects to obtain better performance in their written works.

In addition to the discussion of general performance for both the EG and CG, this study aimed to explore the EG subjects' attitudes toward the BBEWP. The result of the EG students responses to the questionnaire of BBEWP were discussed, as shown in Table 4. To begin with, the subject opinions to the question 41 and 42 indicated that $85 \%$ and $89 \%$ of them considered BBEWP is more convenient than traditional pen-and-paper writing and that they can modify or add content to the first draft more easily. When the subjects are doing their writing on the website, they can always keep the webpage tidy and clean, unlike those done on the paper which sometimes is full of scribbling words and thus appeared messy. Moreover, when the subjects come up with new ideas or intend to do some adjustment of the first draft, they can do it efficiently.

Table 4. Descriptive Statistics Results of the EG's Responses to the Instructional Design of the BBEWPI

\begin{tabular}{|c|c|c|c|c|c|c|c|}
\hline Item & $S A$ & $A$ & $N$ & $D$ & $S D$ & M & $T T L$ \\
\hline 41. $B B E W P$ is more convenient than traditional & 16 & 13 & 3 & 2 & 0 & 4.26 & 34 \\
\hline pen-and-paper writing & $47.1 \%$ & $38.2 \%$ & $8.8 \%$ & $5.9 \%$ & $0 \%$ & & $100 \%$ \\
\hline 42. BBEWP allows me to modify or add content more & 20 & 10 & 2 & 2 & 0 & 4.41 & 34 \\
\hline conveniently & $58.8 \%$ & $29.4 \%$ & $5.9 \%$ & $5.9 \%$ & $0 \%$ & & $100 \%$ \\
\hline 43. BBEWP allows me to search for words or useful & 22 & 10 & 2 & 0 & 0 & 4.59 & 34 \\
\hline sentence patterns if necessary & $64.5 \%$ & $29.4 \%$ & $5.9 \%$ & $0 \%$ & $0 \%$ & & $100 \%$ \\
\hline 44. BBEWP allows me to propose questions on the & 12 & 9 & 12 & 1 & 0 & 3.94 & 34 \\
\hline $\begin{array}{l}\text { website so that I can obtain answers from teachers or } \\
\text { peers }\end{array}$ & $35.3 \%$ & $26.5 \%$ & $35.3 \%$ & $2.9 \%$ & $0 \%$ & & $100 \%$ \\
\hline 45. BBEWP allows me to clarify uncertain vocabulary or & 19 & 13 & 2 & 0 & 0 & 4.50 & 34 \\
\hline sentences if necessary & $55.9 \%$ & $38.2 \%$ & $5.9 \%$ & $0 \%$ & $0 \%$ & & $100 \%$ \\
\hline 46. By observing peers excellent writing on the website, I & 12 & 18 & 3 & 1 & 0 & 4.21 & 34 \\
\hline can understand how to modify my writing & $35.3 \%$ & $52.9 \%$ & $8.8 \%$ & $2.9 \%$ & $0 \%$ & & $100 \%$ \\
\hline 47. BBEWP teacher's assessment allows me to understand & 11 & 18 & 4 & 1 & 0 & 4.15 & 34 \\
\hline the improvement of my writing & $32.4 \%$ & $52.9 \%$ & $11.8 \%$ & $2.9 \%$ & $0 \%$ & & $100 \%$ \\
\hline 48. BBEWP allows me to observe different writing styles & 14 & 19 & 1 & 0 & 0 & 4.35 & 34 \\
\hline made by other students & $41.2 \%$ & $55.9 \%$ & $2.9 \%$ & $0 \%$ & $0 \%$ & & $100 \%$ \\
\hline
\end{tabular}

Notes. $\mathrm{SA}=$ strongly agree, $\mathrm{A}=$ agree, $\mathrm{N}=$ Neutral, $\mathrm{D}=$ Disagree, $\mathrm{SD}=$ Strongly Disagree, $\mathrm{M}=\mathrm{Mean}$

Secondly, according to their responses to the question 43 and $45,93 \%$ and $94 \%$, respectively, of the EG students viewed BBEWP as an useful tool which allows them to search for necessary information while doing their writing. Furthermore, they can clarify the uncertain words or phrases use through the concordance function. The design of BBEWP platform had incorporated the online dictionary checking and concordance examining functions, and they are very convenient for the students to look for any words or phrases they may need to use. Thirdly, the result of the subjects responses to question 47 showed that $62 \%$ the EG subjects agreed that BBEWP website performed an important function for them to exchange ideas or comments with regard to their writing. Whenever they post their writing on the blog, they can receive 
comments or suggestions from either the teacher or peers, which help the subjects to refine their written works. Fourthly, the subject' opinion to the question 46 is that, $91 \%$ of them considered it helpful that they can observe peers written works on the BBEWP website, which may facilitate the students' awareness in respect of how to modify their own writing. This is because when some students produce writing with better quality, assessed by the teacher or peers, they may serve as model samples for other students to inspect and learn. As for the EG subjects responses to question 47 , the result showed that $85 \%$ of them agreed that the teacher's comments on their writing enable them to understand to what extent they have improved in terms of their writing quality. With the teacher's comments of corrective feedback on the BBEWP website, the students are able to compare and analyze the strength and weakness of their writing and therefore accumulate more knowledge regarding what is evaluated as good English writing. Finally, the EG subjects responses to the question 48 revealed that $97 \%$ of the students agreed that BBEWP allow them to observe different writing styles made by other students, and that such function helps them to be aware that there would be a variety of writing styles because of different thinking model from each individual writer. To sum up, most of the subjects showed positive attitude toward BBEWP, for it provides a convenient platform for the students to do their writing task, either upload the assignment or do the necessary addition or modification of the first draft. Besides, BBEWP allows the students to look for information or clarify their puzzles with ease. What's more, students can observe teacher's comments or peers excellent written works simultaneously, which help them develop better understanding how better English wring should be organized.

\section{Conclusion}

Based on the data analysis and discussion of the study result, three major findings with the three research questions are summarized as follows. First, there is significant difference between the EG and the CG's writing performance in the post-test writing. Second, there is no significant difference between the EG and the CG in terms of their responses to the teacher's assessment, and to peer and self assessment. However, the average score for the subjects' responses to the three assessments are higher than 3.65, which means the subjects confirm the efficacy of multi-level writing assessment on improving their writing. Since a significant relationship between the subjects' attitude toward English writing and their writing performance in the post-test was found, a two way ANOVA was executed to examine if there is significant interaction between the treatments and the subjects attitude in the effect of the writing performance. The result indicated that either in the EG or CG, the subjects with more positive writing attitude performed better than those with less positive writing attitude. Third, the EG subjects showed positive attitude toward BBEWP, for it provides a convenient platform for the students to do their writing task, either upload the assignment or do the necessary addition or modification of the first draft. BBEWP also allows the students to look for information or clarify their puzzles with ease. Particularly, students can observe teacher's comments or peers excellent written works simultaneously, which help them develop better understanding how better English wring should be organized.

In view of the study result, several pedagogical implications are suggested. First, teachers can utilize the blog platform to provide EFL learners with an interactive writing environment in which learners can post their writing assignment and then obtain the teacher's corrective feedback as well as peer responses, which helps the learners to take responsibility of their learning. Second, observing peer written works and the teachers' comments on other peers' products on the blog platform is an important process for improving the students' writing performance.

\section{References}

[1] Al-Aayed, B. (2009). Blog assisted language learning: The use of blog in language learning in Saudi schools. Retrieve March, 21, 2010 from http://libback.uqu.edu.sa/hipres/ABS/ind8026.pdf

[2] Arslan, R., \& Sahin-kizil, A. (2010). How can the use of blog software facilitate the writing process of English language learners? Computer Assisted Language Learning, 23(3), 183-197.

[3] Boud, D., \& Falchikov, N. (1989). Quantitative studies of student self-assessment in higher education: A critical analysis of findings. Higher Education, 18 (5), 529-49.

[4] Brown, H., \& Abeywickrama, P. (2010). Language assessment: Principles and classroom practices. San Francisco: San Francisco State University.

[5] Conway, R., Kember, D., Sivan, A., \& Wu, M. (1993). Peer assessment of an individual's contribution to a group project. Assessment and Evaluation in Higher Education, 18, 45-56

[6] Dochy, F., Segers, M., \& Sluijsmans, D. (1999). The use of self-, peer-, and co-assessment in higher education: a review. Studies in Higher Education, 24(3), 331-350.

[7] Edelenbos, P., \& Kubanek-German, A. (2004). Teacher's assessment: The concept of 'diagnostic competence'. Language Testing, 21(3), 259-283

[8] Falchikov, N. (1995). Peer assessment by groups of group work. Assessment and Evaluation in Higher Education, 20 289-300 
[9] Hyland, K. (2003). Second language writing. Cambridge: Cambridge press.

[10] Johns, A. M. (1997). Text, role, and context: Developing academic literacies. Cambridge: Cambridge University Press.

[11] Magin, D., \& Helmore, P. (2001). Peer and teacher's assessments of oral presentation skills: how reliable are they? Studies in Higher Education Volume 26(3), 287-298.

[12] Miceli, T., Murray, S., \& Kennedy, C. (2010). Using an L2 blog to enhance learners'participation and sense of community. Computer Assisted Language Learning, 23(4), 321-341.

[13] Petersen, S.A., Divitini, M., \& Chabert, G. (2008). Identity, sense of community and connectedness in a community of mobile language learners. ReCALL, 20(3), 361-379.

[14] Pinkman, K. (2005). Using blogs in the foreign language classroom: encouraging learner independence. The JALT CALL Journal, 1(1), 12-24.

[15] Stiler, G. (2003). Blogging and blogspots: An alternative format for encouraging reflective practice among preservice teachers. Education, 123(4), 789.

[16] Topping, K. (1998). Peer-assessment between students in colleges and universities. Review of Educational Research, 68, 249-276.

[17] Topping, K. (2003). Self and peer assessment in school and university: reliability, validity and utility. In M. Segers, F. Dochy., \& E. Cascallar (Eds.), Optimizing new modes of assessment: in search of qualities and standard (pp. 55-87). Netherlands: Kluwer Academic Publishers

[18] Ward, J. M. (2004) Blog assisted language learning (BALL): Push button publishing for the pupils, TEFL Web Journal 3(1). Retrieved on February10, 2010, from http://www.esp-world.info/Articles_26/push\%20button\%20pub lishing\%20ward \%202004.pdf

[19] Warschauer, M., \& Kern, R. (2005). Network-based language teaching: Concepts and practice. Cambridge: Cambridge University Press

[20] Weigle, S. C. (2002). Assessing writing. Cambridge: Cambridge University Press. 